\title{
Comparative Study of Methods that Detect Levels of Lead and its Consequent Toxicity in the Blood
}

\author{
Kevin J. Rodriguez ${ }^{1}$, Alicia Alva ${ }^{2}$, Virginia T. Santos ${ }^{3}$, Avid Roman-Gonzalez ${ }^{4}$ \\ Image Processing Research Laboratory (INTI-Lab) $)^{1,2,4}$ \\ Interdisciplinary Research Center Science and Society (CIICS $)^{3}$ \\ Universidad de Ciencias y Humanidades, Lima, Perú ${ }^{1,2,3,4}$
}

\begin{abstract}
The present work is the study of the different methods used to determine the toxicity produced by the presence of a contaminating metal in the blood. Mainly, the presence of lead in the blood was taken as a reference to focus the work, knowing that metals like Cadmium $(\mathrm{Cd})$ and Mercury $(\mathrm{Hg})$ are also toxic to health and the environment. Although the information is extensive on the methods to be studied and in some cases it is not detailed to define each process, a comparative study of the most relevant and currently used methods can be carried out, taking into account that the choice will be defined according to the main characteristics of each one. Although all agree to be electrochemical processes, there are details to know which method to choose, either by sensitivity, economic or even structural factors, such as having a laboratory for its development. Environmental pollution with toxic elements is very harmful to health, even in small quantities can be very dangerous. These can be present in rivers, soil and even in the air, and these spaces are more than enough to contaminate the human being since these particles adhere in both cases for many years. It is a problem until today and therein lies the importance of the study.
\end{abstract}

Keywords-Blood lead; toxicity; voltammetry; absorption spectroscopy; healthcare

\section{INTRODUCTION}

According to the World Health Organization (WHO), lead is included in the list of 10 chemicals that cause serious public health problems, so that the intervention of the Member States is necessary to safeguard the health of workers, children and women of childbearing age. The Institute of Health and Sanitary Evaluation has estimated that, according to the data updated in 2015, exposure to lead was responsible for 494,550 deaths [1] and became the loss of 9.3 million Disabilityadjusted life year (DALY), which is understood as a measure of the global disease. The exposure to lead according to the data was responsible for $12.4 \%$ of the global burden of intellectual disability, $2.5 \%$ of the overall burden of the quality of ischemic heart disease (is the disease caused by arteriosclerosis of the coronary arteries, which are responsible for supplying blood to the heart muscle), and the last $2.4 \%$ of the global burden of stroke. In Peru, there are high levels of lead toxicity in some districts of the capital where industrial areas cause greater health effects. Among the materials produced by these factories are chemical products in general, metal handling, grinding of non-metallic industrial metals, recovery of lead and alloys, which are the main responsible for the environmental impact that have been increasing in recent decades.

International standards admit a maximum level of $0.5 \mathrm{ug} /$ $m^{3}$ [2], a higher value than this will be a problem to attack. The danger of a toxic element in the blood, being able to detect and, above all, provide a follow-up, is an objective for the future and an analytical method so that the amount of lead that many people's body goes through can be identified and taken into account. They had an experience, but not only for the human being, but for all the species within the habitable ecosystem in which we live. This neurotoxin has a direct relationship with health problems [3], such as learning deficit, reduction of intellectual abilities, damage to the central nervous system, muscle pain, weakening of the bones and, in general, the damage to the immune system and the central nervous system. The high exposure to $\mathrm{Pb}$ in pregnant women can cause premature abortions, with an intoxication higher than $10 \mathrm{dl} / \mathrm{mg}$, the probability of decreasing fertility increases. Analogously, in men it can cause discomfort in the reproductive organ. One of the damages [4] that can cause in the man is the reduction of the spermatozoa and the decrease of the fertility.

Recent studies in children from 1 to 13 years old developed between March and April 2017 [2] in the district of Callao-Lima resulted in a high proportion of children contaminated with lead. This was because of the construction material of their homes, the consumption of food, toys, state of conservation of the house paint and many other forms that seem to be harmless but they are not. There are several methods of analysis, each of them, the problem and the interest in the evidence. Our interest is, in effect, an economical and practical method for the measurement of this toxic element. The objective of the study is the meaning of the construction of each method and help you to select the most appropriate procedure to achieve a specific objective, since we all have the characteristic of having electronic, physical and chemical engineering as elements of studies and we do it. There is no doubt that with the use of current technology it will be possible to create new and better methods of analysis; although it is difficult to find the description. 


\section{ANALYSIS OF DifFERENT METHODS FOR THE DETERMINATION OF LEAD IN BLOOD}

There are several methods to determine the lead in the blood, each one of these data of use. In this part, some of these aspects are mentioned below.

\section{A. Atomic Absorption Spectrophotometry $(A A S)$}

In this technique, the sample to be analyzed is vaporized and the element of interest is atomized at elevated temperatures. To determine the concentration of the element, the wavelength absorbed by it is measured after being subjected to incident light [5]. This method is one of the most common analytical techniques used to calculate the determination of an analyte [6]. Specifically, it can be said that the atoms that are initially in a fundamental state, go to a state of excitation by absorbing energy, jumping from one level of energy to another level so that they then return to their normal state. This process of jumping energy level and returning to its normal state is known as absorption and emission, with which generate specific wavelength patterns.

1) Flame Atomic Absorbtion Spectroscopy (FAAS): Its foundation is the absorption of radiation energy by free radical atoms. The process contains several stages, so a hollow cathode light source that can emit a very short wavelength is necessary. This lamp is very much used for this type of experience, since it will be the one that will excite the analyte. Once the light of the lamp hits the analyte, as see in Fig. 1, there will be a decrease in the number of photons, which will then be sent to the monochromator to be able to divide the different wavelengths, which will eventually pass to the detector to convert the photons obtained in an electrical signal [7].

2) Graphite Furnace Atomic Absorption (GFAAS or ETAAS): This is also known as electrothermal atomization. This method is the most sensitive within the Atomic Absorption Spectrophotometry (AAS). The sample is placed inside a graphite tube, as see in Fig. 2, to which a potential difference is applied which allows us to obtain the necessary energy for the atomization [8] that is, the atoms of an element absorb energy heating them and achieving vaporization of the sample becoming free atoms. The graphite tube is aligned with a light from a spectral lamp. The atomic vapor produced by the sample located inside the graphite tube will absorb the light emitted by the spectral lamp. It should be mentioned that a similar result could also be achieved with a continuous source and a high-resolution spectrometer, although the absorbance signal lasts a maximum of 5 seconds and generates a transient peak from which a calibration curve can be constructed [9].

3) Hydride Generation Atomic Absorption Spectrophotometry (HGAAS): Knowing that atomic absorption spectrometry is one of the most common methods that helps us determine the presence of metals in a sample, here we mention one more procedure, called atomic absorption spectrometry, as see in Fig. 3, with the generation of hydrides or abbreviated as HGAAS. The analyte is passed to a form of gas hydride, which will later go through an atomization process inside a chamber containing argon (Ar). After the atomization process is needed an external stimulus to the resulting analyte, in this case the generator of hydride with which we can measure its absorbance [10].

\section{B. Voltammetric Methods}

This method [11] is based on the pre-concentration of the analyte in the working electrode, after which a potential is applied during which the analyte is withdrawn from the solution. Finally, the response obtained is proportional to the concentration analyzed.

1) Anodic Stripping Voltammetry (ASV): Within the known voltammetric methods, we will begin to talk about ASV, commonly called "STRIPPING", is an electrochemical process that seeks to relate the behavior of a sample in the form of a current signal, applying a potential difference from anode to cathode [12]. This potential difference will cause a change in the sample adhered to the electrodes, as see in Fig. 4, making it oxidize or reduce.

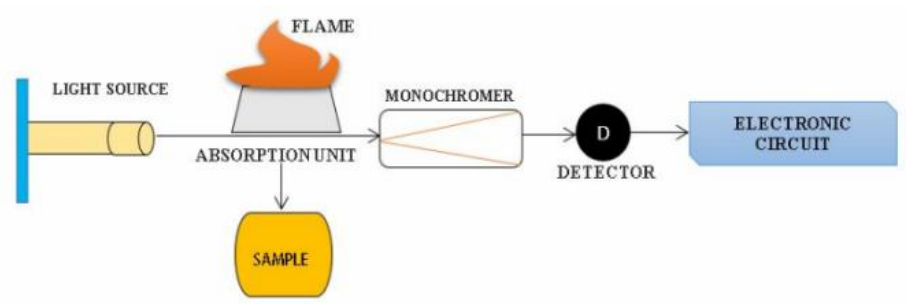

Fig. 1. All the System is Constituted for a Light Source, Absorption unit, Flame, Monochrome, Detector and the Electronic Circuit that will be in Charge of Processing the Information.

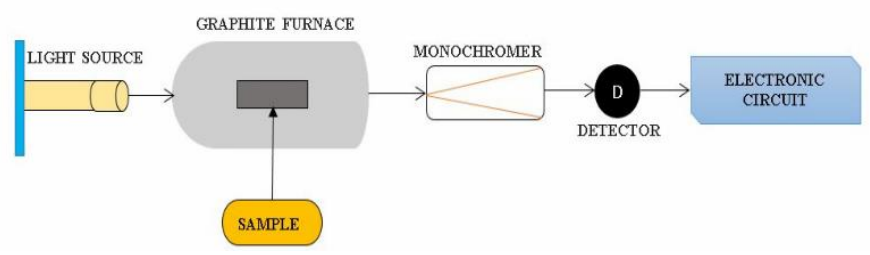

Fig. 2. A Light is Emitted by a Light Source, and this Light Strikes the Atomized Sample the Monochromator Selects the Wavelength of Interest the Detector Measures the Amount of Absorption and the Electronic Circuit Processes the Information.

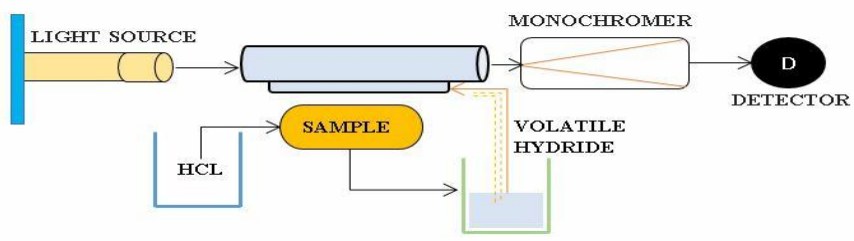

Fig. 3. The Presented Scheme is Composed for a Light Source, a Monochromer, a Detector and a Hydride Generator in other Cases, you can Appreciate an Optic Cell, a Double Beam Instruments and Even a Constant Flame. 


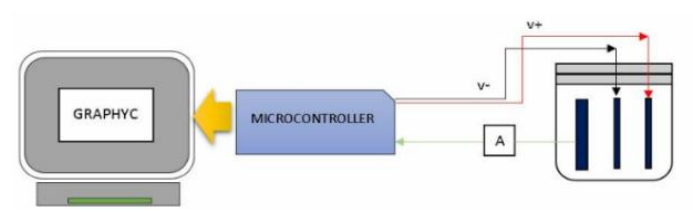

Fig. 4. Block Diagram of the Process, there are Three Electrodes Connected and the Data is Sent to the Microcontroller.

2) Cathodic Stripping Voltammetry (CSV): Within the voltammetric methods, Cathodic Stripping Voltammetry (CVS) [13] can also be found which is mainly applied in the analysis of low levels of analyte or sample and to compounds containing sulfur. Comparing with Anodic Stripping Voltammetry (AVS) in which a potential difference is applied to generate a positive sweep, here the analyte is preconcentrated in the electrode with a few drops of mercury. In order to carry out the experience, this is based on the measurement of a reductive current response based on the sweep performed in the negative direction, for which a reference potential is previously applied and thus the analyte behavior can be analyzed.

3) Adsorptive Stripping Voltammetry (AdSV): Following with the voltammetric methods, the extraction method is based on the accumulation of ions or compounds to be determined in the working electrode. As well as Anodic Stripping Voltammetry and Cathodic Stripping Voltammetry, [14] we can achieve the accumulation by adsorption of the species in the working electrode, as see in Fig. 5, and that there are compounds that have adsorption properties. It can be carried out on most of the electrodes used in voltammetry for which it is possible to reproduce it throughout the measurement process, assuring a constant surface.

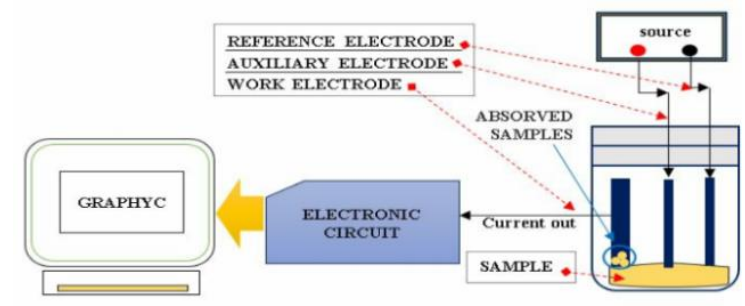

Fig. 5. Basic Scheme of Connection - Adsorptive Stripping Voltammetry (AdSV).

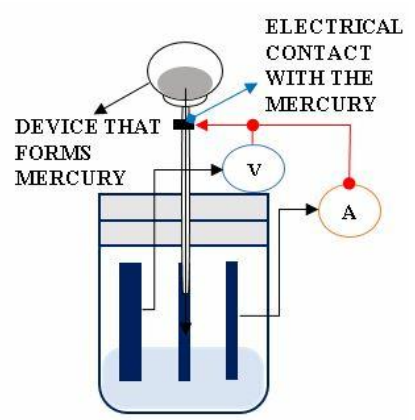

Fig. 6. The Image Shows the Container that Drops Mercury through a Capillary Tube to the Sample the Connections of the Voltmeter and the Ammeter to the Electrodes and to a Point Placed in the Capillary Tube.

\section{Polarography}

This electrochemical process is a method derived from voltammetry, which contains characteristics similar to electrolysis, but instead of eliminating an unwanted component of a solution. On the other hand, the polarography [15] keeps the sample, as it was in order to be able to recover it while small currents are applied in less time. Created in 1922 by Jaroslav Heyrovský, polarography is a specific type of measurement found within the linear sweep Voltammetry where the potential of the electrode is altered from the initial potential to the end. The attractiveness of this method is that several properties of the mercury, as seen in Fig. 6, which will fulfill the function of an electrode, are derived. The elegance of this method [16] are the various properties of mercury as an electrode material. Because it is a liquid material, it provides an easy revocability and reproducibility of the surface.

\section{COMParative STUdY}

In the previous comparative table, the main characteristics of each method developed in this work will be mentioned below. This table will serve as a guide to identify what method to use in any future study that you want to do.

As we can see in Table I, Graphite Furnace Atomic Absorption method is more expensive than the aforementioned voltammetric methods, and it is useful for small samples in the $u g / l$ range. In addition to this, a laboratory with the necessary equipment is important because the sample must be subjected to various processes before being able to analyze the result. Similar to GFAAS, the Flame Atomic Absorption Spectroscopy method requires a laboratory and equipment to carry out the experience. Analyze trace metals. This method, unlike the graphite furnace, can detect larger quantities in the $m g / l$ range. Hydride Generation Atomic Absorption Spectrophotometry improves the detection of the analyte that is analyzed, in turn, it supports interferences produced in the process, but it needs a stage of generation of hydride and laboratory materials to be able to develop the experience with which it becomes a costly process. Anodic Stripping Voltammetry is an inexpensive process and good sensitivity, used to analyze metals present in a sample. Its operation is easy, precise and portable for the analysis of blood. Cathodic Stripping Voltammetry as well as the ASV is of low cost and good sensitivity. It is worth mentioning that it is not necessary to add reagents to the sample to be analyzed. Adsorptive Stripping Voltammetry is a method with good sensitivity and inexpensive. It can present problems in the current measurements since it is susceptible to the interference of other substances present in the sample, so we must be careful with the substances to analyze.

Finally, the Polarography method is a low cost process and of good precision compared to the CSV or ASV methods. This method is longer and more complex than the aforementioned methods. The attractiveness of this method is that it uses an electrode as the working electrode subjected to drops of mercury (EGM), which makes it essentially different from other voltammetric methods. 
TABLE I. COMPARATIVE TABLE OF THE METHODS FOR THE DETERMINATION OF LEAD

\begin{tabular}{|l|l|l|l|l|l|}
\hline Methods & $\begin{array}{l}\text { Fixed laboratory } \\
\text { environment }\end{array}$ & $\begin{array}{l}\text { Portable laboratory } \\
\text { environment }\end{array}$ & Low cost & High cost \\
\hline Flame Atomic Absorption Spectroscopy & $\mathrm{X}$ & & $\mathrm{X}$ \\
\hline Graphite Furnace Atomic Absorption & $\mathrm{X}$ & & & $\mathrm{X}$ \\
\hline Hydride Generation Atomic Absorption Spectrophotometry & $\mathrm{X}$ & & $\mathrm{X}$ & $\mathrm{X}$ \\
\hline Anodic Stripping Voltammetry & & $\mathrm{X}$ & $\mathrm{X}$ & \\
\hline Cathodic Stripping Voltammetry & & $\mathrm{X}$ & $\mathrm{X}$ & $\mathrm{X}$ \\
\hline Adsorptive Stripping Voltammetry & & $\mathrm{X}$ & $\mathrm{X}$ & $\mathrm{X}$ \\
\hline Polarography & & $\mathrm{X}$ & $\mathrm{X}$ & $\mathrm{X}$ \\
\hline
\end{tabular}

\section{DISCUSSION}

It is mention that all the methods shown in the present work fulfill a common objective which is to determine the concentration of a specific analyte present in a sample. A major difference of some methods over others is the need for a laboratory and expensive equipment. We must take into account the degree of sensitivity that is required, the efficiency and precision that is desired to be able to use the most correct method. Highlighting all the analyzed models, voltammetry since they are possible methods of reproducing and assembling according to the case of study analysis, allowing in its construction process to understand electronics, physics, chemistry and biology, including its practicality of mobilization and low cost.

\section{CONCLUSIONS}

In this research work, we presented the different methods to determine the presence of toxic metal in the blood, we can conclude that in the process of voltammetry, there is the advantage that the electrodes occupy very small surfaces and the applied potential will generate low currents, which will be easy to measure. Finally, in voltammetry, only a small amount of sample is needed, while in the others the sample is converted to another state through vaporization processes, atomization or generation of hydrides.

\section{FUTURE WORK}

In this work, we present an initial and fundamental comparative study of the most used methods for the detection of heavy metals in the blood. Our future interest is the construction of an electronic device that allows us to take measures on this problem, so that this study allows to understand the variants of each existing model, knowing the advantages and disadvantages to advance towards its manufacture. For our process, the ASV method is the choice to build the device in the short term, the main idea being to detect levels of $\mathrm{Pb}$ in the blood, nowadays it is a social problem in many places of Peru.

\section{ACKNOWLEDGMENT}

We want to thank the Image Processing Research Laboratory (INTI-Lab) and the Universidad de Ciencias y Humanidades (UCH) for their support in this research. Also, to the National Fund for Scientific, Technological and Technological Innovation (FONDECYT), according to the contract "N ${ }^{\circ} 091-2018$-FONDECYT-BM-IADT-AV" for the financing of this project and the Electronics Laboratory of the $\mathrm{UCH}$ for assigning us their facilities and being able to carry out the respective tests.

\section{REFERENCES}

[1] World Health Organization, "Questions and answers: international lead poisoning prevention awareness campaign week of action 22-28 october $2017, " 2017$.

[2] M. Morales, Juan, MD, MgSc, PHD; Fuentes-Rivera, José, MD, MgSc, PHD; Bax, Vincent, Ing, MgSc; Matta, Hernán H, MD, MgSc, PHD; Delgado-Silva, Carlos Alberto, MD, "Niveles de plomo sanguíneo y factores asociados en niños residentes de un distrito del Callao," AVFT, vol. 37, no. 2, 2018.

[3] A. Evens et al., "The impact of low-level lead toxicity on school performance among children in the Chicago Public Schools: a population-based retrospective cohort study," Environ. Heal., vol. 14, no. 1, p. 21, Dec. 2015.

[4] Agency for Toxic Substances and Disease Registry, Toxicological Profile for Lead, Draft for Public Comment. 2019.

[5] N. P. Cheremisinoff, "Elemental and structural characterization tests," in Polymer Characterization, Elsevier, 1996, pp. 43-81.

[6] W. Yawar, "Determination of wear metals in lubricating oils by flame atomic absorption spectrophotometry," J. Anal. Chem., vol. 65, no. 5, pp. 489-491, May 2010.

[7] T.Alasadi, "Flame atomic absorption", Wasit University, Tech.Rep., 140, 2016.

[8] Paul Riemann Cruz Ausejo and Indira Consuelo Nájera Gálvez, "Evaluación del contenido microbiológico y cuantificación de plomo en pinturas faciales infantiles obtenidas en el Mercado Central de Lima. Setiembre 2015," universidad nacional mayor de san marcos, 2017.

[9] J. A. Holcombe and D. L. G. Borges, "Graphite Furnace Atomic Absorption Spectrometry," in Encyclopedia of Analytical Chemistry, Chichester, UK: John Wiley \& Sons, Ltd, 2010.

[10] B. Stephen, "Studies of essential and non-essential elements in cerealbased weaning foods for infants commercially available on the ghanaian market," University of Ghana, 2013.

[11] P. Worsfold et al., "Voltammetry | Stripping Voltammetry," Encycl. Anal. Sci., pp. 238-257, Jan. 2019.

[12] M. R. J. and J. B.-O. J Barón-Jaimez, "Anodic stripping voltammetryASV for determination of heavy metals," 2nd Int. Meet. Res. Mater. Plasma Technol., 2013.

[13] E. P. Achterberg, M. Gledhill, and K. Zhu, "Voltammetry-Cathodic Stripping,” Ref. Modul. Chem. Mol. Sci. Chem. Eng., Jan. 2018.

[14] R. Kalvoda, "Adsorptive Stripping Voltammetry in Trace Analysis," in Contemporary Electroanalytical Chemistry, Boston, MA: Springer US, 1990, pp. 403-405.

[15] Shodhganga, "General principle of polarography," 1980, pp. 27-28.

[16] S. Al-Amri and B. H. A. Al-Ameri, "Differential Pulse Polarography Procedure for the Estimation of Deferoxamine in Pharmaceuticals Voltammetry View project Analytical chemistry View project," Chem. Sci. Trans., vol. 7, no. 2, pp. 272-281, 2018. 